\title{
On the scientific justification of the use of working hours, child labour and property rights in social life cycle assessment: three topical reviews
}

\author{
Rickard Arvidsson • Henrikke Baumann • \\ Jutta Hildenbrand
}

Received: 1 June 2014 / Accepted: 5 November 2014 /Published online: 14 November 2014

(C) Springer-Verlag Berlin Heidelberg 2014

\begin{abstract}
Purpose Working hours, child labour and property rights have been suggested as topics to assess in social life cycle assessment (SLCA). The purpose of this study is to investigate the scientific justification of the current use of these topics. The long-term aim is to contribute to the future development of SLCA.

Methods A literature review was conducted for each of the three topics. One thousand scientific articles were analysed for each topic, and relevant articles were selected. The articles were analysed based on whether the topics facilitated or obstructed beneficial social values, and whether they facilitated or obstructed adverse social values.

Results and discussion The results show that the three topics both facilitate and obstruct beneficial social values. They also show that the topics both facilitate and obstruct adverse social values. Considering the complex and ambiguous nature of these topics reported in the scientific literature, the current use of these topics in the SLCA literature is found not to be completely scientifically justified.

Conclusions Based on this study, the current use of working hours, child labour and property rights in SLCA studies should be questioned. We suggest that the fields of social science and economics may be fruitfully considered when seeking scientific justification for topics to assess in SLCA.
\end{abstract}

Keywords Child labour · Intellectual property rights $\cdot$ LCA . SLCA $\cdot$ Unemployment $\cdot$ Working time

Responsible editor: Marzia Traverso

R. Arvidsson $(\bowtie) \cdot H$. Baumann $\cdot$ J. Hildenbrand

Environmental Systems Analysis, Chalmers University of

Technology, Rännvägen 6, 41296 Gothenburg, Sweden

e-mail: rickard.arvidsson@chalmers.se

\section{Introduction}

Social life cycle assessment (SLCA) is getting increasing attention in the life cycle assessment (LCA) community. The main idea behind SLCA is to assess social impacts of products or services in a similar manner as environmental impacts are assessed in conventional, environmental LCA (ELCA). Together with life cycle costing (LCC), ELCA and SLCA are sometimes combined to form the overarching method of life cycle sustainability assessment (LCSA) (Valdivia et al. 2013). The term SLCA was first used by O'Brien et al. (1996) and was there described as complementary to ELCA. Norris (2006) discussed the scope of SLCA, focusing mainly on human health impacts. Weidema (2006) discussed the potential of quality-adjusted life years (QALYs) as social indicator in SLCA. Dreyer et al. (2006) also discussed the scope of SLCA, suggesting an increased focus on companies' conducts rather than on production processes and material flows. Jørgensen et al. (2008) reviewed the SLCA literature at that time, concluding that there was a considerable variation in suggested approaches. Parent et al. (2010) also conducted a review of existing SLCA approaches, again concluding that a considerable difference among the approaches existed at that time. In 2009, a group of researchers organized in the life cycle initiative of the United Nation Environment Programme (UNEP) and the Society for Environmental Toxicology and Chemistry (SETAC) published a report presenting guidelines for SLCA (Benoit et al. 2009). This publication is hereafter referred to as the UNEP/SETAC guidelines. In 2011, methodological sheets were published as a supplementary document for public consultation (Benoit-Norris et al. 2011). The document was updated according to feedback, is available online as a pre-publication version (Benoit Norris et al. 2013) and is hereafter referred to as the methodological sheets. A number of LCA case studies have since then been conducted, some 
that claim to follow the UNEP/SETAC guidelines, and some that do not (Table 1). The methodological variations that can be found in these case studies suggest the need for further methodological discussions in the SLCA field. This need was also identified in the UNEP/SETAC guidelines, in which elaboration of social indicators was one specifically identified area for future research. It is this research need to which this study aims to contribute.

An important feature of impact assessment in ELCA is its foundation in the natural sciences as described by, for example, Hauschild and Wenzel (1998). Environmental impacts such as global warming, acidification, eutrophication, ozone depletion and energy use can be found in almost any basic environmental science textbook; see for example Miller and Spoolman (2013). Environmental indicators such as the life cycle global warming potential of a product can thus be said to rest on a natural science foundation. It is widely acknowledged that indicators should rest on a scientific basis, and this applies for sustainability (Meadows 1998; Rametsteiner et al. 2011), ecological (Niemeijer and de Groot 2008) and social (Noll 2002) indicators. In line with this, Dahl (2012) writes that sustainability indicators convey scientific information and that the scientific underpinning of such indicators should be strengthened. The suggested subcategories in the UNEP/SETAC guidelines and specific social indicators suggested in the methodological sheets are adopted from political standards and documents published by international organizations, such as the United Nations (UN), the Global Reporting Initiative (GRI), the Organisation for Economic Co-operation and Development (OECD) and the International Labour Organization (ILO). This implies an agreement of the UNEP/ SETAC guidelines and the methodological sheets with such political documents. It also implies that the UNEP/SETAC guidelines' subcategories and indicators are mainly based on political consensus. However, a scientific evaluation of suggested subcategories and subsequent indicators is not available in the UNEP/SETAC guidelines, nor in the methodological sheets.

In a previous article, some of us pointed out that some social topics recommended and applied in the SLCA field could be interpreted differently depending on cultural background and on political, ethical and ideological views (Baumann et al. 2013). In this article, our aim is to further motivate that claim and deepen the analysis by investigating the scientific justification of three social topics suggested in the UNEP/SETAC guidelines: working hours, child labour and property rights. In order to meet our aim, we performed a review of the scientific literature for the three topics. In Sect. 2, the method of the literature review is presented. This

Table 1 Overview of conducted SLCA case studies with regards to whether they claim to follow the UNEP/SETAC guidelines, and whether they include any if the social topics of working hours, child labour and property rights

\begin{tabular}{|c|c|c|c|}
\hline Study & Product studied & $\begin{array}{l}\text { Claims to follow } \\
\text { UNEP/SETAC } \\
\text { guidelines }\end{array}$ & $\begin{array}{l}\text { Include any of the three } \\
\text { social topics studied }\end{array}$ \\
\hline $\begin{array}{l}\text { Baumann et al. } \\
\text { (2013) }\end{array}$ & Airbag & No & None \\
\hline $\begin{array}{l}\text { Bouzid and Padilla } \\
\text { (2014) }\end{array}$ & Tomatoes & No & $\begin{array}{l}\text { Working hours } \\
\text { Child labour }\end{array}$ \\
\hline $\begin{array}{l}\text { Ciroth and Franze } \\
\text { (2011) }\end{array}$ & Laptop & Yes & $\begin{array}{l}\text { Working hours } \\
\text { Child labour } \\
\text { Property rights }\end{array}$ \\
\hline $\begin{array}{l}\text { Ekener-Petersen } \\
\text { and Finnveden (2013) }\end{array}$ & Laptop & Yes & $\begin{array}{l}\text { Working hours } \\
\text { Child labour } \\
\text { Property rights }\end{array}$ \\
\hline $\begin{array}{l}\text { Franze and Ciroth } \\
\text { (2011) }\end{array}$ & Cut roses & Yes & $\begin{array}{l}\text { Working hours } \\
\text { Child labour }\end{array}$ \\
\hline $\begin{array}{l}\text { Hosseinijou et al. } \\
\text { (2014) }\end{array}$ & Building materials & Yes & Child labour \\
\hline Hunkeler (2006) & Detergents & No & Working hours \\
\hline Macombe et al. (2013) & Biodiesel & No & None \\
\hline Manik et al. (2013) & Palm oil & Yes & $\begin{array}{l}\text { Working hours } \\
\text { Child labour }\end{array}$ \\
\hline $\begin{array}{l}\text { Martínez-Blanco et al. } \\
\text { (2014) }\end{array}$ & Fertilizers & Yes & $\begin{array}{l}\text { Working hours } \\
\text { Child labour }\end{array}$ \\
\hline Musaazi et al. (2014) & Sanitary pads & No & None \\
\hline Weldegiorgis and Franks (2014) & Steel & No & None \\
\hline
\end{tabular}


is followed by Sects. $3-5$, with results presented for working hours, child labour and property rights, respectively. The implications of the results are discussed in each section. In Sect. 6, recommendations for future SLCA studies and method development are provided.

Before proceeding, a note on terminology may be relevant. The UNEP/SETAC guidelines use the term stakeholder category to denote the social entities that can be impacted by product life cycles. These are workers, consumers, local community, society and value chain actors. They further use the term subcategory to denote ways by which the stakeholder categories can be impacted. Among those subcategories are the three topics investigated in this article, that is working hours, child labour and property rights. A subcategory thus specifies an area of interest for a specific stakeholder category. They further use the term inventory indicator to denote specific operationalizations of subcategories. This could be, for example, hours of work per person and week for the subcategory working hours. We prefer the term social topic to denote working hours, child labour and property rights. This is because the term subcategory is not, to our knowledge, used anywhere outside the SLCA field, and our three reviews in this article cover several other scientific fields. We mean the term topic to denote ways by which social entities can be impacted and for which more specific indicators can be derived, and we only use the term subcategory in connection to the UNEP/SETAC guidelines. By the term indicator, we mean an operationalization of a topic, which is in line with the use of the term indicator in the UNEP/SETAC guidelines. It is also in line with the definition that an indicator is a system variable or parameter of particular interest or importance that are used in order to guide societal action (Gallopín 1996). This is also in agreement with the definition provided by Frønes (2007), who defines indicators as signs of social concern and also acknowledges that indicators can focus on positive social aspects rather than on concerns only. For the case of working hours, for example, we would thus say that working hours is the social topic, and hours of work per person and day, or hours per functional unit, is an example of a social indicator for the topic.

\section{Methods}

\subsection{Literature selection}

This study comprises three topical literature reviews. The topics reviewed are working hours, child labour, and property rights. These three were selected among the numerous social topics described in the SLCA literature and in the UNEP/ SETAC guidelines in particular for a number of reasons. Most importantly, the three topics have been applied in several SLCA case studies (Table 1). Working hours is the most frequently applied social topic and is even the only topic applied in one case study (Hunkeler 2006). Child labour is frequently used as example in the main text of the UNEP/ SETAC guidelines. In addition, the current use of child labour as topic for assessment in SLCA has been discussed and criticized (Clift et al. 2013; Jørgensen et al. 2010), which makes it interesting to investigate further. Property rights is included because it is a social topic which is less related to the production system and to the work required in order to produce a product compared to working hours and child labour. The studied set thus contains topics which are frequently used in SLCA case studies, discussed within the SLCA field, and inherently different.

For each of the topics, we begin by reviewing how they have been discussed in the SLCA literature, primarily in the conducted case studies in Table 1 and in the UNEP/SETAC guidelines. In particular, we outline whether the three topics were considered to be beneficial or adverse in these studies.

Then, we conduct a review of the non-SLCA scientific literature. This scientific literature was obtained through searches on "working hours", "child labour OR child labor" and "property rights" in the web-based scientific database Science Direct (http://www.sciencedirect.com/). This search revealed large bodies of research, with about 20,000 publications on working hours, about 3,000 publications on child labour, and almost 26,000 publications on property rights. From that, we considered the first 1000 hits for each topic, in the order they appeared according to relevance in the database. From these 1000 publications, studies that were considered to be of high relevance based on the content of their titles were selected. High relevance here means that the publication seemed to make some clear statement regarding beneficial or adverse societal impacts from working hours, child labour or property rights. The articles were then subject to further relevance scrutiny by consideration of their abstracts and main text. In the end, only tens of articles clearly positioning any of the three topics as socially beneficial or adverse were identified. Although these reviews are not exhaustive, they provide an overview of the three topics.

In addition to the SLCA literature and the hits from Sciencedirect, we also included two other publications of high relevance for the topic of child labour. The first is the article about child labour by Nieuwenhuys (1996). The second is a study of the cocoa product chain by Borg and Selmer (2012), in which views on child labour by local Africans are reported.

\subsection{Content analysis}

The selected publications from the literature search were analysed through content analysis, searching for attributions of positive and negative societal values to any of the three topics in a similar way as was also done by Boholm and Arvidsson (2014) and Boholm et al. (2014). If any of the three 
topics were reported to cause or facilitate $x$, where $x$ is something socially desirable, the topic was regarded as socially beneficial with regards to $x$. Contrary, if any of the three topics were reported to prevent or obstruct $x$, where $x$ is something socially desirable, the topic was regarded as socially adverse with regards to $x$. In addition, if any of the three topics were reported to cause or facilitate $y$, where $y$ is something socially unwanted, the topic was regarded as socially adverse with regards to $y$. And, finally, if any of the three topics were reported to prevent or obstruct $y$, where $y$ is something socially unwanted, the topic was regarded as socially beneficial with regards to $y$. Note that the classification of something that the topics contribute to as socially desirable or unwanted was not done by the authors of this article but deduced from the writing of the reviewed studies. We did no deductions between adverse values caused and beneficial values obstructed, or between beneficial values caused and adverse values obstructed. This means that we did not assume that because a topic caused a beneficial value (e.g. happiness), it also obstructed the opposite, adverse value. This was done since we wanted to present the literature review results as unbiased as possible, and since it was in many cases difficult to tell the exact opposite of both adverse and beneficial values.

For the case of working hours, some of the literature was all about specific health care professions, such as surgeons and nurses, and about their specific working situations. While societal impacts from working hours for such professions are interesting, we decided to exclude that type of very profession-specific literature since the SLCA literature does not focus on specific professions but rather considers working hours in general.

Findings are presented qualitatively since this communicates the diversity and nuances of the findings better than quantitative presentations. Table 2 summarizes the findings, showing beneficial and adverse social values that are facilitated or obstructed by reductions and increases of working hours, child labour and property rights.

\section{Working hours}

\subsection{Working hours in the SLCA literature}

Working hours is the time spent on paid labour. It is the only social topic considered in the first SLCA case study, conducted by Hunkeler (2006). He calculated the geographical distribution of working hours for two detergents. It can be deduced from the writing that Hunkeler (2006) means it to be beneficial for a country to have many working hours. Working hours are reported to constitute a means to, and even a potential proxy indicator for, welfare aspects such as housing and health care.
Using the same approach, Bouzid and Padilla (2014) calculated the working time per functional unit for tomatoes.

Working hours is also included as a subcategory in the UNEP/SETAC guidelines and is further specified in the methodological sheets as "excessive hours of work" for the stakeholder category worker. Ekener-Petersen and Finnveden (2013) wrote that working hours emerged as an important topic from interviews with stakeholder groups but did not write whether the stakeholders wanted more or fewer working hours. Franze and Ciroth (2011) quantified the (adult) working hours to be $72-84 \mathrm{~h} /$ week and worker for roses grown in Ecuador, and $38 \mathrm{~h} /$ week and worker for roses grown in the Netherlands. They further classified the working hours in Ecuador to have a "very negative effect", and the working hours in the Netherlands to have an "indifferent effect" for the stakeholder workers. It thus seems clear that they considered many working hours to be adverse. A clear statement regarding reference point was reported by Ciroth and Franze (2011) to be $8 \mathrm{~h}$ per day and $48 \mathrm{~h}$ per week, which is based on the methodological sheets. The methodological sheets in turn refer to a discussion paper from an expert meeting on the measurement of decent work by the International Labour Organization (2008).

Manik et al. (2013) used the term "decent working hours", indicating that the working hours should not be too many. What the term "decent" refers to is not clarified but may again refer to the document by the International Labour Organization (2008). Martínez-Blanco et al. (2014) provided information on working hours in two different ways. They aggregated the working hours needed per functional unit as in the same way as Hunkeler (2006). Then, they used that as a basis to calculate the occurrence of occupational lethal and non-lethal accidents. They also used information on working hours per person and week from the so-called Social Hotspot Database and included that in a separate evaluation of social risks. Social risk was then defined as more than $48 \mathrm{~h}$ per person and week, same as by Ciroth and Franze (2011).

Employment, and its opposite unemployment, is a topic much interlinked with working hours. "Local employment" is a subcategory suggested in the UNEP/SETAC guidelines for the stakeholder category local community. This topic is included in the studies by Ciroth and Franze (2011), EkenerPetersen and Finnveden (2013), Franze and Ciroth (2011), Hosseinijou et al. (2014) and Weldegiorgis and Franks (2014). Employment is also mentioned as important for human well-being by Norris (2006) and Musaazi et al. (2014).

\subsection{Working hours in other scientific literature}

In the non-SLCA scientific literature, several studies investigated the relationship between working hours, happiness and health. Knabe and Rätzel (2010) investigated the influence of working hours on happiness in Germany. They found it to be 


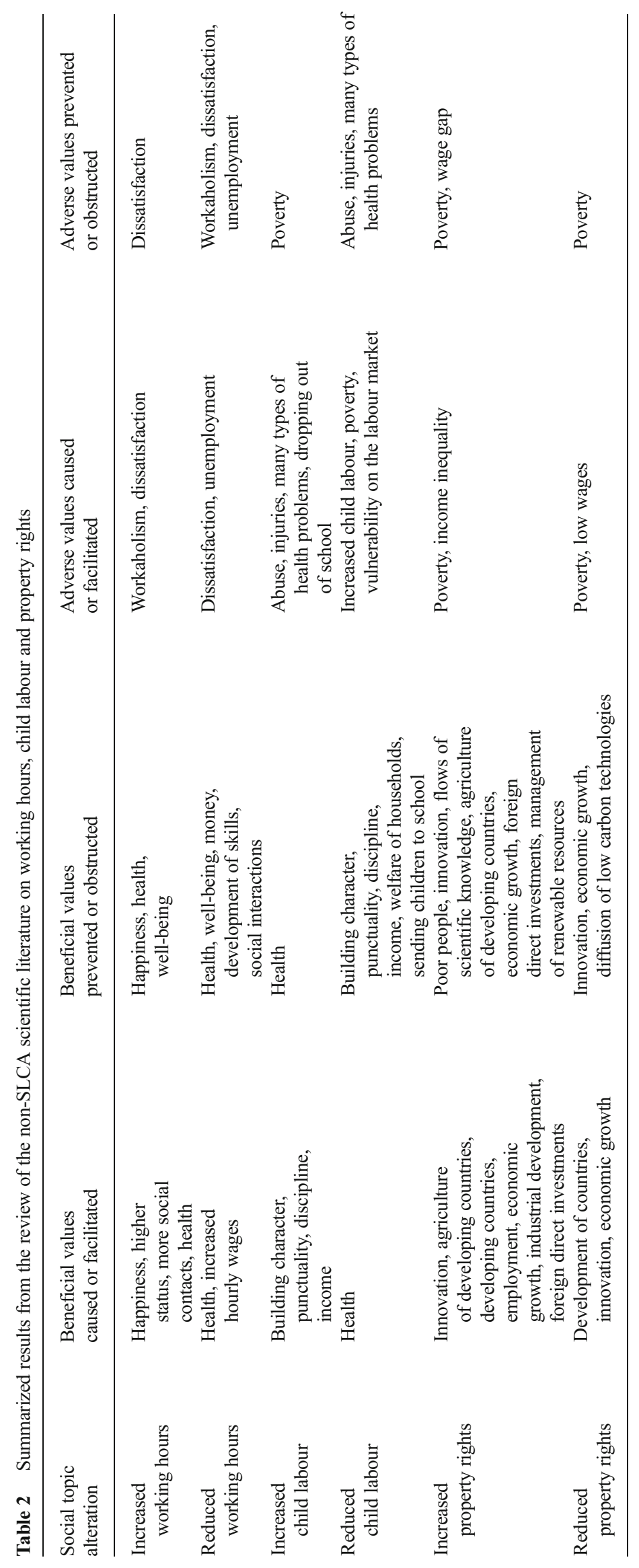


an inverse $\mathrm{U}$ shape. When increased from a low level, additional working hours increase happiness, possibly due to higher status and more social contacts. Additional working hours did, however, affect happiness negatively. Several other studies also reported that working hours and ill health typically follow an inverse U-shaped relationship and that excessive working hours can cause health problems (Newcombe 2007). Reduced health can thus be caused by both increased and reduced working hours. Accordingly, increased health can be obtained by both increasing and reducing working hours. The extremes of high working hours, such as workaholism or other types of heavy work investments, are clearly deteriorating for health and personal happiness (Snir and Harpaz 2012).

Wunder and Heineck (2013) wrote about individual preferences regarding working hours, and about working hour mismatches among couples in Germany. They wrote that self-reported well-being is significantly reduced if there is a mismatch between preferred and actual working hours and that this reduction is larger for self-perceived underemployment. This is because underemployment causes losses in money, less development of skills and fewer social interactions. Within couples, both partners tend to get reduced wellbeing if one partner is underemployed. Nabe-Nielsen et al. (2010) wrote that for the case of eldercare workers, a misfit between actual and preferred working hours was associated with dissatisfaction. They also noted that when the work takes place is important. For example, they wrote that night work has been associated with various negative health outcomes, which is in accordance with other authors (Costa 2011).

A number of authors discussed flexible working hours. Costa and Sartori (2005) wrote that low individual flexibility and variable working hours (that is, flexible from the perspective of the employer) is associated with poor health and well-being. Based on interviews in the computer industry, MacEachen et al. (2008) wrote that flexible working hours may increase the overall work intensity.

The relationship between working hours per person and unemployment has been discussed in several studies. Marimon and Zilibotti (2000) modelled the effect of working hour reductions on unemployment. They found that small reductions in working hours resulted in small reductions in unemployment, whereas larger reduction of working hours resulted in increased unemployment. Sánchez (2013) wrote about the working hour reduction from 48 to $45 \mathrm{~h}$ per week implemented in Chile in 2005. He found that this reduction had no effect on unemployment. The model calculations by Altavilla et al. (2005) resulted in a persistent increase in unemployment following a working hour reduction in Germany and the USA. Raposo and van Ours (2010) studied the work hour reduction from 44 to $40 \mathrm{~h}$ per week in Portugal and found both positive and negative impacts for workers. The hourly wages increased, keeping monthly wages almost constant, but workers working less than $40 \mathrm{~h}$ per week became more likely to become unemployed.

\subsection{Discussion on working hours}

In the SLCA field, there seems to be a fundamental difference between the operationalization of the topic working hours by Hunkeler (2006) on one hand, and the methodological sheets on the other hand. The former quantifies the number of working hours per functional unit, and the latter quantifies the working hours per person and week. While the former seems to focus on that it is beneficial if more working hours per functional unit is located within a region, the latter seems to focus on that more working hours per person and week are socially adverse for the stakeholder worker, at least when it exceeds a threshold level. The topic of local employment suggested in the UNEP/SETAC guidelines is considered beneficial for the stakeholder local community in all SLCA case studies that included this topic.

The non-SLCA scientific literature on working hours and employment seems to suggest a delicate balance between working too much, causing stress and other health problems, and working too little, with the extreme of unemployment and subsequent losses of salary and well-being as result. This balance is individual, and one crucial aspect seems to be the degree of freedom one has to distribute the working hours over time. There also seems to be a complex correlation between working hours and unemployment, with some studies suggesting that reduced working hours increase unemployment, and some studies suggesting the opposite. Since there are studies that point towards a mutual exclusiveness, including both working hours and local employment in SLCA studies without reflecting upon this correlation could lead to "both have your cake and eat it" type of results and conclusion. Working hours and local employment are linked to two different stakeholder categories in the UNEP/SETAC guidelines, namely workers and local community, respectively. However, the non-SLCA scientific publications reviewed here rather suggest that an individual worker is just as adversely affected by unemployment as the local community in general, if not more.

It should be noted that the above cited research on working hours is largely focused on so-called developed countries. There is much less research conducted on working hours in so-called developing countries. In so-called developing countries, where working hours are sometimes higher than in socalled developed countries per person and week, any problems related to increased working hours should be more profound. However, incomes are also typically lower, so any problems from reduced working hours and subsequent loss of income should be more profound as well.

The results from the review of working hours in the nonSLCA scientific literature are summarized in Table 2. 
Depending on the specific situation and on personal preferences, increased working hours can facilitate happiness, higher status, more social contacts and improved health, as well as obstruct dissatisfaction. However, increased working hours can also obstruct happiness, health, and well-being, as well as facilitate workaholism and dissatisfaction. Reduced working hours can facilitate health and increase hourly wages and also obstruct workaholism, dissatisfaction and unemployment. However, reduced working hours can also obstruct health, well-being, money, development of skills and social interactions, and facilitate dissatisfaction and unemployment. Overall, this summary points to a difficulty in applying working hours as a social topic in SLCA due to its ambiguous nature. It can also be concluded that the problem of working too little for the worker is not given much room in the SLCA literature, despite being clearly articulated in the scientific literature.

\section{Child labour}

\subsection{Child labour in the SLCA literature}

Child labour is the employment of people under a certain age (Ambadekar et al. 1999). The definition can also include that the work conducted is mentally, physically, socially or morally dangerous and harmful to children and prevents them from attending school (International Labour Organization and Inter-Parliamentary Union 2002). In the UNEP/SETAC guidelines, it is clear that much child labour is considered to be socially adverse. There is sometimes, however, references to "illegal child labour" rather than just "child labour". It is thus somewhat unclear whether child labour is considered socially adverse only if it does not comply with local laws, or always. Child labour is included as a topic by EkenerPetersen and Finnveden (2013) and Hosseinijou et al. (2014), but they do not write about how they interpret it. Franze and Ciroth (2011) and Ciroth and Franze (2011) include child labour and describe it as a "negative social effect", thereby clarifying their interpretation. Manik et al. (2013) refer to child labour as a form of "discrimination", which suggests that they consider child labour to be socially adverse. Martínez-Blanco et al. (2014) include the risk of child labour as a social indicator, indicating a negative perception.

There are two publications in the SLCA field that presented different perspectives on child labour. Jørgensen et al. (2010) assessed the validity of the impact pathway proposed for child labour in contemporary SLCA approaches. They concluded that the mere existence of child labour says little about whether there are negative or positive impacts on children and society. Clift et al. (2013) wrote that considering child labour as something that eschews supply chains is valid if the alternative to child labour is education, but not if the alternative is prostitution or enforced military.

\subsection{Child labour in other scientific literature}

There are several records of children suffering from child labour in the non-SLCA scientific literature. Ambadekar et al. (1999) studied child labourers below the age of 15 years in India. They found that the children had significantly lower body mass index (BMI) and delayed genital development compared to non-child labourers of the same age, concluding that labour at young age has a deleterious effect on the growth of children. Bose-O'Reilly et al. (2008) studied children working with small-scale gold mining, sometimes at ages as low as 7 years. They found that these children had typical symptoms of mercury intoxication due to the use of mercury in the smallscale gold mining and concluded that child labour with hazardous substances such as mercury should be stopped. The problems of child labour in small-scale mining, primarily health-related, were further described by Hilson (2008). Gharaibeh and Hoeman (2003) studied child labour (age below 16 years) in Jordan industry. They found that the interviewed children were poor and dropped out of school to assist their parents financially. They further write that the children were exposed to various health hazards, including inhalation of chemicals and physical injuries, along with physical, verbal and sexual abuse. Mehta et al. (1985) studied child labour in Bombay, India, finding that many children were malnourished and worked more than $12 \mathrm{~h}$ per day. Öncü et al. (2013) describe various forms of abuse of children (age below 18 years) working in factories in Turkey. These abuses included physical, emotional and sexual abuse, and these abuses happened more frequently for children than for other workers. Rojas et al. (2010) reported on several healthand comfort-related problems of child labourers (age 1217 years) in Venezuela, including headache, stress, fatigue, feet ache, leg ache, shoulder ache, heat discomfort, noise and repetitive work. Wolff and Maliki (2008) reported on adverse health impacts for child labourers (age 10-15 years) in Indonesia.

There are also studies highlighting socially beneficial aspects of child labour. Dessy and Pallage (2005) divided child labour into "worst" and "other" forms. The other, non-worst forms are labour that help to build the child's "character" in terms of punctuality, discipline and other valued social qualities. They listed some typical child labour in so-called developed countries to illustrate this, such as newspaper delivery, babysitting and part-time farm work. The worst forms are labour which is clearly harmful for the child. They proceeded by arguing that economic research suggests that prohibiting or reducing harmful child labour does not have positive social impacts. They wrote that the reason for this is that poverty has been proven to be the cause of child labour, and poverty 
implies that any extra income is highly needed. Therefore, they concluded, reducing or prohibiting child labour without some mitigation to cover for lost income would be socially undesirable.

This perspective has support from other studies as well. Based on an economic model, Ranjan (1999) wrote that poverty is the cause of child labour in so-called developing countries. He further showed that banning child labour can reduce the welfare of households in so-called developing countries, thereby preventing any ambitions to send children to school. Similarly, Basu and Zarghamee (2009) wrote that based on their economic analysis, a boycott of products produced by child labour may very well cause increased rather than reduced total child labour. The study by Mehta et al. (1985) that reported on child labour in Bombay, India, also wrote that preventing the children from working would probably worsen the conditions of both the children and their families unless some alternative source of income was introduced. Borg and Selmer (2012) interviewed a number of actors along the cocoa production chain, who gave differing views on child labour. Some representatives from a larger company considered child labour to be a considerable sustainability challenge, but farmers and other local groups situated in Ghana did not consider it to be a challenge. Nieuwenhuys (1996) wrote that the connotation of child labour as being adverse lowers the perceived value of their work. In the long run, she wrote, this increases their vulnerability on the labour market and excludes them from the production of value, thereby further reinforcing their vulnerability.

\subsection{Discussion on child labour}

It seems clear that a high amount of child labour is considered an adverse social impact in most SLCA literature, with no distinction being made between different forms of child labour. Only the studies by Jørgensen et al. (2010) and Clift et al. (2013) described that child labour can be beneficial in some cases, or at least more beneficial than the alternative. There are also a number of examples of harmful child labour in the non-SLCA scientific literature. Indeed, reading such records would cause concern in most readers. However, the non-SLCA scientific literature on child labour also suggests that child labour differs in terms of harmfulness to children. Some forms of child labour may even be considered beneficial in terms of building character, providing income and empowering the children. It also seems that reduced child labour could cause increased poverty.

Table 2 summarizes the results from the review of the nonSLCA scientific literature on child labour. According to some studies, child labour may facilitate building of character, punctuality and discipline and provides an income. Some studies also report that it obstructs poverty. However, according to other studies, increased child labour also facilitates abuse, injuries and many types of health problems, increases the probability of the child dropping out of school, and obstructs health. Reducing child labour facilitates health and obstructs abuse, injuries and many types of health problems according to some studies. However, it is also reported to obstruct building of character, punctuality, discipline, income and welfare of households and facilitates increased poverty and vulnerability on the labour market. Furthermore, some studies write that through increased poverty, efforts to reduce child labour can paradoxically facilitate more child labour (Ranjan 1999; Basu and Zarghamee 2009).

This summary of contradicting reports points to problems of using child labour as a topic in SLCA due to its inverse Ushaped nature. A certain amount of child labour, corresponding maybe to a part-time or summer job, seems to be beneficial for building of character and learning discipline and punctuality. Little or no child labour may result in poverty in regions where neither parents nor society has sufficient financial resources to provide for the child. The distinction of child labour into the worst forms and other not so problematic or even beneficial forms, which was suggested by Dessy and Pallage (2005), is not done in most SLCA literature. In accordance with Jørgensen et al. (2010), we thus conclude that the mere incidence of child labour tells little about whether it is adverse or beneficial. A deep understanding of the social context of the child labour is needed in order to tell whether a specific type of child labour is beneficial or adverse. In addition, problems of loss of income from reduced child labour are not included in the SLCA literature, although they may be crucial for the child labourer and his or her family.

\section{Property rights}

\subsection{Property rights in the SLCA literature}

Property rights are law-enforced rules for how resources are owned and used. In the UNEP/SETAC guidelines, "respect of intellectual property rights" is a suggested subcategory for the stakeholder category value chain actors. The term "respect" indicates that intellectual property rights are considered to be beneficial from a social point of view. This subcategory was included in the studies by Ciroth and Franze (2011) and Ekener-Petersen and Finnveden (2013). Jørgensen et al. (2008) mentioned "violation of property rights" as a social topic. Here as well, it seems that property rights are considered socially beneficial, but the reference is to property rights in general, and not to intellectual property rights specifically. Considering that the focus on intellectual property rights is not consistent throughout the whole SLCA literature, the focus of this study has been on property rights in general rather than on intellectual property rights only. 


\subsection{Property rights in other scientific literature}

Saint-Paul (2004) conducted economic modelling to analyse whether intellectual property rights can be regarded "fair" in terms of not afflicting the poor. He wrote that the poor may be adversely affected in the long run by stronger intellectual property rights due to lower innovation. However, he also recommended redistribution by taxes, rather than altered property rights, to address equity concerns. There are an additional number of studies that have discussed the influence of property rights on innovation. The economic model by Gangopadhyay and Mondal (2012) suggested that stronger intellectual property rights may discourage innovation due to the hindrance of flows of scientific knowledge. Hudson and Minea (2013) wrote that the relationship between intellectual property rights and innovation is complex, depending also on the economic growth of the country. Chen and Puttitanun (2005) developed an economic model for the influence of stronger intellectual property rights on innovation in socalled developing countries specifically and found a positive relationship. Chu et al. (2014) developed an economic model showing that the optimal level of intellectual property rights is dependent on the development of the country, with weak intellectual property rights facilitating imitation at an early stage of development, but stronger intellectual property rights encouraging domestic innovation at a later stage. Akiyama and Furukawa (2009) showed an inverse U-shaped relationship between intellectual property rights and innovation in socalled developing countries, implying an optimal level of intellectual property rights there.

Additional studies discussed the influence of property rights on so-called developing countries. Unruh (2002) wrote that the relationship between poverty and property rights in so-called developing countries is complex. Although there is much economic value in informal, undocumented property owned by the poor in so-called developing countries, particularly in land, such property has previously often been utilized by many individuals as a common, and a transfer of property rights to one or some individuals would deprive others the right to use the land. Galiani and Schargrodsky (2010) wrote that in Argentina, providing some households with property rights reduced their poverty compared to other households. Fergusson (2013) suggested that powerful landowners in rural developing countries may use weak property rights to impoverish peasants and make them work for low wages. Perrin (1999) wrote that stronger intellectual property rights may both improve or damage the agriculture of developing countries. The economic model by Lai and Qiu (2003) showed that if so-called developing countries adopt the same strong intellectual property rights as so-called developed countries, both would benefit. Another economic model by Dinopoulos and Segerstrom (2010) showed that strong intellectual property rights lead to permanent increase in technology transfer to so- called developing countries, along with increased employment in so-called developing countries and reduced wage gaps between so-called developed and developing countries.

The influence of property rights on economic growth is another popular theme in the literature. Economic modelling by Chu and Peng (2011) suggested that stronger intellectual property rights do lead to increased economic growth, but also to income inequality. Branstetter et al. (2011) showed that stronger intellectual property rights spurred industrial development of multinational enterprises in the USA. However, the economic modelling by Furukawa (2007) suggested the opposite, that stronger intellectual property rights are not increasing economic growth. Voigt and Gutmann (2013) wrote that the relationship between property rights and growth is complex but that property rights can cause increased economic growth provided that their enforcement is considered trustworthy by private actors. The study by Bose et al. (2012) suggested an inverse U shape relationship between property rights and economic growth. Stronger enforcement of property rights seems to increase economic growth to a certain point, at which growth begins to decline. This implies the existence of optimal property rights with regard to economic growth.

Several studies discuss whether property rights spur foreign direct investment in so-called developing countries. Foreign direct investment is the investment into production or business in a country by a company or individual from another country. Based on a study of strengthened property rights in Taiwan, Lo (2011) wrote that foreign direct investment was indeed increased. However, the economic model by Glass and Saggi (2002) suggested that intellectual property rights in socalled developing countries did not increase foreign direct investment. Mathew and Mukherjee (2014) conducted economic modelling showing that the relationship between intellectual property rights and foreign direct investment is complex, although they wrote that stronger property rights in a socalled developing country can cause reduced foreign direct investments.

Several studies relate property rights to spreading of green technology and management of natural resources. In a review study, Rai et al. (2014) concluded that weak property right can hinder the diffusion of low-carbon technologies, especially cutting-edge technologies. For more mature technologies, however, property rights had little effect. Adger and Luttrell (2000) wrote about the importance of property rights for wetland conservation. But, rather than advocating the typical private type property rights, they argue that wetland resources may be better managed as a common property. This discussion about natural resources, where private and common property rights are contrasted, is a theme in several studies. By quantitative modelling of deforestation and soil quality in Indonesia, Fernandez (2006) showed that private and common property rights may equal each other in terms of 
sustainable resource management. The economic modelling by McAfee and Miller (2012) rather indicated that property rights can be less efficient than commons for managing scarce, renewable resources.

Ending this section with two other interesting positions, Grossman (2005) argued that intellectual property rights are generally too strong. This is because people spend too much time guarding their ideas (i.e. intellectual property) from piracy, time which could otherwise have been spent on developing new ideas, thereby creating more value for society. Menon et al. (2014) studied a transfer of property rights to women in Vietnam. This transfer leads to decreased illness among children, increased health insurance, increased school enrolment, and reallocation of household expenditures towards food and away from alcohol and tobacco, which was more dominating when property was possessed by males. Perhaps then the strength of property rights is less important than which gender that holds them?

\subsection{Discussion on property rights}

In the SLCA literature, property rights are often stated as something beneficial that should be respected. A strong focus in the UNEP/SETAC guidelines is on intellectual property rights, whereas material property rights are not addressed. The non-SLCA scientific literature on property rights is more diverse. This may partly be because of the many different types of properties that exist, spanning from the very first documented property right, which is the purchase of the Cave of the Patriarchs by the biblical Abraham in the seventeenth century BCE (Rosenberg and Weiss 2012), to more recently property rights on the Moon (von der Dunk et al. 2004). Intellectual property and land are two frequently discussed types of properties in the non-SLCA scientific literature. A number of studies have investigated whether stronger property rights have a positive influence on fairness, innovation, economic growth, foreign direct investment, and the development of developing countries. For all these aspects, results are ambiguous, some suggesting a positive correlation with stronger property rights, some a negative correlation, and others inverse U shapes.

As summarized in Table 2, increased property rights can facilitate innovation, agriculture of developing countries, developing countries in general, employment, economic growth, industrial development, and foreign direct investments. It can also obstruct poverty and wage gaps. However, increased property rights also obstruct poor people, innovation, flows of scientific knowledge, agriculture of developing countries, economic growth, foreign direct investments and management of renewable resources, and it also facilitates poverty and income inequality according to the reviewed non-SLCA studies. Reducing property rights facilitates development of countries, innovation and economic growth and obstructs poverty and low wages. However, it also facilitates poverty and obstructs innovation, economic growth and diffusion of low-carbon technologies. The ability of property rights to bring both beneficial and adverse developments makes it ambiguous as a topic for social indicators, and its current use in SLCA studies cannot be said to be fully scientifically justified.

\section{Conclusions and recommendations}

The SLCA literature seems to suggest that working hours and child labour are socially adverse for the stakeholder worker, but property rights socially beneficial for the stakeholder local community. However, when reviewing the non-SLCA scientific literature to investigate which effects working hours, child labour and property rights actually have on social entities, a more complex picture emerges. It is not so simple that these three topics can be categorized as socially beneficial or adverse for these stakeholders. Rather, there is support in the non-SLCA scientific literature, presented in Sects. 3-5, that the relationship between these topics and social entities is complex. Table 2 shows how these topics contribute to both socially beneficial and adverse developments, for both individuals and for society as a whole. Indeed, social topics can be positive or negative depending on the specific situation and on values (Dahl 2012). This is contrary to the environmental impact categories in ELCA, where few books and articles on environmental science would suggest that, for example, emissions of greenhouse gas emissions and toxic substances are also beneficial for the environment. Note also that some influences of the topics on people or society are not captured in their contemporary use in SLCA. For example, contemporary use of working hours and child labour in SLCA does not consider problems related to loss of income. Although loss of income is partly captured in other subcategories in the UNEP/ SETAC guidelines, this still makes the subcategories working hours and child labour ambiguous.

This ambiguousness and complexity of the three reviewed topics make us question their current use in SLCA. We cannot see that there is complete scientific justification for the way these topics are currently used in the SLCA literature. Current uses of the three topics in SLCA even run the risk of appearing over-simplistic from a social science perspective. By extension, it raises concerns about the system of stakeholders, subcategories and indicators in current applications of SLCA in general.

We therefore recommend additional development of and discussions about topics for assessment and specific social indicators in SLCA. Such developments and discussions should be done in consideration of the scientific justification of the topics and indicators. Ideally, if the same analysis as 
shown in Table 2 was conducted for an optimal social topic or indicator, a less ambiguous result should emerge. If a topic defined as socially adverse is increased, it should preferably not result in any facilitation of beneficial values. Similarly, increasing beneficial topics should not facilitate any adverse social values.

In the same way as ELCA draws on the natural sciences, it would seem logic that SLCA would draw heavily on the social sciences. Some of the advantages of that could be a greater clarity in underlying assumptions about the social realm, along with richer descriptions of social topics. The nonSLCA scientific literature reviewed here is mainly from the fields of social science and economics, including development studies, ergonomics, anthropology, labour economics and development economics. We find it likely that the fields of social science and economics may contain additional valuable insights for the development social topics and indicators for SLCA. For example, Lehmann et al. (2011) sought inspiration and indicators from the field of social impact assessment (SIA) when assessing social impacts of water resource management and packaging waste management. An overview of how different fields of social science, including economic geography, management science and sociology, view product life cycles is presented by Boons et al. (2012). Insights from such fields that also consider product life cycles may be of relevance to SLCA. The recently developed field of happiness studies, devoted to studies of the subjective well-being of humans, may also be relevant to consider (see for example the Journal of Happiness Studies and articles within).

Within development of impact assessment methods in ELCA, impact pathway is a central concept, for example in the articles on water use impact assessment by Milà i Canals et al. (2009) and Boulay et al. (2011). Impact pathways connect the product life cycle to entities impacted or areas of protection. Jørgensen et al. (2010) attempted to construct impact pathways for child labour and well-being based on a number of social science sources. They found both topics to lack valid impact pathways. Their study illustrates the importance of constructing impact pathways as a basis for social impact assessment, since it requires the analyst to be specific about how the product life cycle impacts social entities via social topics. The social science literature described above may provide bases for such impact pathways. A clear connection to scientifically valid impact pathways can hopefully ensure that social topics and indicators are unambiguous and scientifically justified (see the schematic Fig. 1 for an illustration).

Note, however, that social topics are typically less clear-cut than environmental issues when it comes to determining what is a positive and what is a negative impact. The same indicator value could be considered as either beneficial or adverse depending on values and context. Depending on the knowledge perspective employed, even the understanding of what
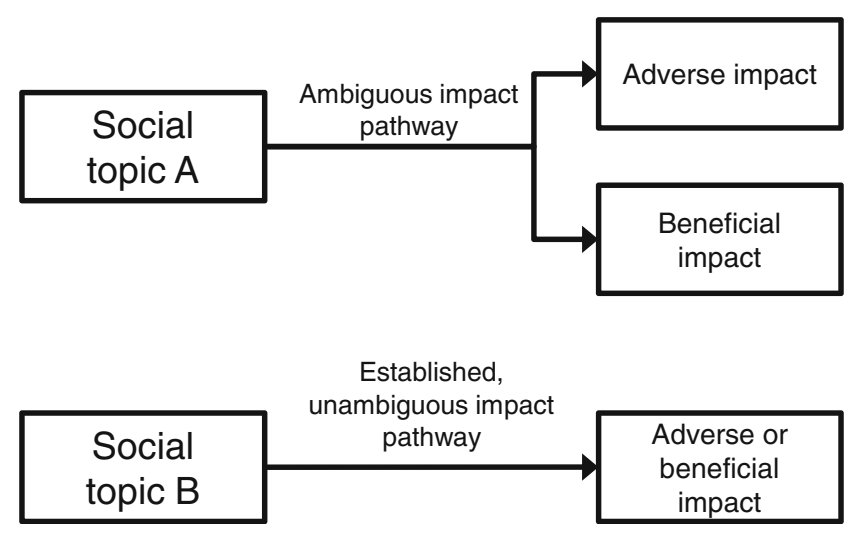

Fig. 1 Schematic illustration of social impact pathways that connect the product life cycle to social entities impacted via social topics. Social topic $\mathrm{A}$ is ambiguous as it causes both adverse and beneficial impacts, whereas social topic B has an unambiguous impact pathway that leads exclusively to adverse or beneficial impacts (not both)

constitutes "objectivity" can differ greatly. Concepts such as cause-effect chains are related to the systems perspective and are contested by, for example, an interpretive social constructivist stance (Gorton 2010). Such differences in scientific perspectives must be considered when venturing into the fields of social science. For introductions to the differences in perspectives between the natural and social sciences, we recommend the electronic article by Gorton (2010) and the book chapter by Baumann (2009).

We hope that these recommendations will provide inspiration for scientifically justified social topics and indicators in the SLCA field.

\section{References}

Adger WN, Luttrell C (2000) Property rights and the utilisation of wetlands. Ecol Econ 35(1):75-89

Akiyama T, Furukawa Y (2009) Intellectual property rights and appropriability of innovation. Econ Lett 103(3):138-141

Altavilla C, Garofalo A, Vinci CP (2005) Evaluating the effects of working hours on employment and wages. J Policy Model 27(6): $647-664$

Ambadekar NN, Wahab SN, Zodpey SP, Khandait DW (1999) Effect of child labour on growth of children. Public Health 113(6):303-306

Basu K, Zarghamee H (2009) Is product boycott a good idea for controlling child labor? A theoretical investigation. J Dev Econ 88(2):217220

Baumann H (2009) Don't fence me in.... In: Boons F, Howard-Grenville $\mathrm{J}$ (eds) The social embeddedness of industrial ecology. Edward Elgar Publishing, Cheltenham

Baumann H, Arvidsson R, Tong H, Wang Y (2013) Does the production of an airbag injure more people than it saves in traffic? Discussing an alternative approach to S-LCA methodology. J Ind Ecol 17(4):517527

Benoît C, Mazijn B, Andrews ES, Barthel L-P, Beck T, Ciroth A, Cucuzzella C, Gensch C-O, Hébert J, Lesage P, Manhart A, Mazeau P, Methot A-L, Moberg A, Norris G, Parent J, Prakash S, Reveret J-P, Spillemaeckers S, Ugaya CML, Valdivia S, Weidema 
BP (2009) Guidelines for social life cycle assessment of products. United Nations Environment Programme and Society of Environmental Toxicology and Chemistry, Nairobi

Benoit-Norris C, Vickery-Niederman G, Valdivia S, Franze J, Traverso M, Ciroth A, Mazijn B (2011) Introducing the UNEP/SETAC methodological sheets for subcategories of social LCA. Int J Life Cycle Assess 16(7):682-690

Benoît Norris C, Traverso M, Valdivia S, Vickery-Niederman G, Franze J, Azuero L, Ciroth A, Mazijn B, Aulision D (2013) The Methodological Sheets for Sub-Categories in Social Life Cycle Assessment (S-LCA). United Nations Environment Programme (UNEP) and Society for Environmental Toxicology and Chemiastry (SETAC)

Boholm M, Arvidsson R (2014) Controversy over antibacterial silver: implications for environmental and sustainability assessments. J Clean Prod 68:135-143

Boholm M, Arvidsson R, Boholm Å, Corvellec H, Molander S (2014) Dis-Ag-reement: the construction and negotiation of risk in the Swedish controversy over antibacterial silver. J Risk Res. doi:10. 1080/13669877.2013.879492

Boons F, Baumann H, Hall J (2012) Conceptualizing sustainable development and global supply chains. Ecol Econ 83:134-143

Borg J, Selmer JK (2012) From Ghana to Magnum Ice Cream: tracking down the organisation of sustainable cocoa product chains Gothenburg. Chalmers Univeristy of Technology

Bose N, Murshid AP, Wurm MA (2012) The growth effects of property rights: the role of finance. World Dev 40(9):1784-1797

Bose-O'Reilly S, Lettmeier B, Matteucci Gothe R, Beinhoff C, Siebert U, Drasch G (2008) Mercury as a serious health hazard for children in gold mining areas. Environ Res 107(1):89-97

Boulay A-M, Bulle C, Bayart J-B, Deschênes L, Margni M (2011) Regional characterization of freshwater use in LCA: modeling direct impacts on human health. Environ Sci Tech 45(20):8948-8957

Bouzid A, Padilla M (2014) Analysis of social performance of the industrial tomatoes food chain in Algeria. New Medit 13(1):60 65

Branstetter L, Fisman R, Foley CF, Saggi K (2011) Does intellectual property rights reform spur industrial development? J Int Econ 83(1):27-36

Chen Y, Puttitanun T (2005) Intellectual property rights and innovation in developing countries. J Dev Econ 78(2):474-493

Chu AC, Peng S-K (2011) International intellectual property rights: effects on growth, welfare and income inequality. J Macroecon 33(2):276-287

Chu AC, Cozzi G, Galli S (2014) Stage-dependent intellectual property rights. J Dev Econ 106:239-249

Ciroth A, Franze J (2011) LCA of an ecolableded notebook-consideration of social and environmental impacts along the entire life cycle. GreenDeltaTC GmbH, Berlin

Clift R, Sim S, Sinclair P (2013) Sustainable consumption and production: quality, luxury and supply chain equity. In: Jawahir IS, Sikdar SK, Huang Y (eds) Treatise on sustainability science and engineering. Springer Netherlands, Dordrecht, pp 291-309

Costa G (2011) Editorial for special issue of applied ergonomics on working hours. Appl Ergon 42(2):193-195

Costa G, Sartori S (2005) Flexible work hours, ageing and well-being. Int Congr Ser 1280:23-28

Dahl AL (2012) Achievements and gaps in indicators for sustainability. Ecol Indic 17:14-19

Dessy S, Pallage S (2005) A theory of the worst forms of child labour. Econ J 115(500):68-87

Dinopoulos E, Segerstrom P (2010) Intellectual property rights, multinational firms and economic growth. J Dev Econ 92(1):13-27

Dreyer LC, Hauschild MZ, Schierbeck J (2006) A framework for social life cycle impact assessment. Int J Life Cycle Assess 11(2):88-97
Ekener-Petersen E, Finnveden G (2013) Potential hotspots identified by social LCA - part 1: a case study of a laptop computer. Int J Life Cycle Assess 18(1):127-143

Fergusson L (2013) The political economy of rural property rights and the persistence of the dual economy. J Dev Econ 103:167-181

Fernandez L (2006) Natural resources, agriculture and property rights. Ecol Econ 57(3):359-373

Franze J, Ciroth A (2011) A comparison of cut roses from Ecuador and the Netherlands. Int J Life Cycle Assess 16(4):366-379

Frønes I (2007) Theorizing indicators. Soc Indic Res 83(1):5-23

Furukawa Y (2007) The protection of intellectual property rights and endogenous growth: is stronger always better? J Econ Dyn Control 31(11):3644-3670

Galiani S, Schargrodsky E (2010) Property rights for the poor: effects of land titling. J Public Econ 94(9-10):700-729

Gallopín GC (1996) Environmental and sustainability indicators and the concept of situational indicators. A systems approach. Environ Model Assess 1:101-117

Gangopadhyay K, Mondal D (2012) Does stronger protection of intellectual property stimulate innovation? Econ Lett 116(1):80-82

Gharaibeh M, Hoeman S (2003) Health hazards and risks for abuse among child labor in Jordan. J Pediatr Nurs 18(2):140-147

Glass AJ, Saggi K (2002) Intellectual property rights and foreign direct investment. J Int Econ 56(2):387-410

Gorton W (2010) The philosophy of social science, http://www.iep.utm. edu/soc-sci/. Encyclopedia of Philisophy. Accessed 07132014

Grossman HI (2005) Inventors and pirates: creative activity and intellectual property rights. Eur J Polit Econ 21(2):269-285

Hauschild M, Wenzel H (1998) Environmental assessment of products, volume 2. Chapman and Hall, London

Hilson G (2008) 'A load too heavy': critical reflections on the child labor problem in Africa's small-scale mining sector. Child Youth Serv Rev 30(11):1233-1245

Hosseinijou S, Mansour S, Shirazi M (2014) Social life cycle assessment for material selection: a case study of building materials. Int J Life Cycle Assess 19(3):620-645

Hudson J, Minea A (2013) Innovation, intellectual property rights, and economic development: a unified empirical investigation. World Dev 46:66-78

Hunkeler D (2006) Societal LCA methodology and case study. Int J Life Cycle Assess 11(6):371-382

International Labour Organization (2008) Measurement of decent work. International Labour Office, Geneva

International Labour Organization and Inter-Parliamentary Union (2002) Eliminating the worst forms of child labour: a practical guide to ILO Convention No. 182 Handbook for parliamentarians No. 3. International Labour Office, Geneva

Jørgensen A, Le Bocq A, Nazarkina L, Hauschild M (2008) Methodologies for social life cycle assessment. Int J Life Cycle Assess 13(2):96-103

Jørgensen A, Lai LCH, Hauschild MZ (2010) Assessing the validity of impact pathways for child labour and well-being in social life cycle assessment. Int J Life Cycle Assess 15:5-16

Knabe A, Rätzel S (2010) Income, happiness, and the disutility of labour. Econ Lett 107:77-79

Lai ELC, Qiu LD (2003) The North's intellectual property rights standard for the South? J Int Econ 59(1):183-209

Lehmann A, Russi D, Bala A, Finkbeiner M, Fullana-i-Palmer P (2011) Integration of social aspects in decision support, based on life cycle thinking. Sustainability 3(4):562-577

MacEachen E, Polzer J, Clarke J (2008) "You are free to set your own hours": governing worker productivity and health through flexibility and resilience. Soc Sci Med 66(5):1019-1033

Manik Y, Leahy J, Halog A (2013) Social life cycle assessment of palm oil biodiesel: a case study in Jambi Province of Indonesia. Int J Life Cycle Assess 18(7):1386-1392 
Marimon R, Zilibotti F (2000) Employment and distributional effects of restricting working time. Eur Econ Rev 44:1291-1326

Martínez-Blanco J, Lehmann A, Muñoz P, Antón A, Traverso M, Rieradevall J, Finkbeiner M (2014) Application challenges for the social Life Cycle Assessment of fertilizers within life cycle sustainability assessment. J Clean Prod 69:34-48

Mathew AJ, Mukherjee A (2014) Intellectual property rights, southern innovation and foreign direct investment. Int Rev Econ Financ 31: $128-137$

McAfee RP, Miller AD (2012) The tradeoff of the commons. J Public Econ 96(3-4):349-353

Meadows D (1998) Indicators and information systems for sustainable development -A Report to the Balaton Group. Hartland Four Corners, The Sustainablility Institute

Mehta MN, Prabhu SV, Mistry HN (1985) Child labor in Bombay. Child Abuse Negl 9(1):107-111

Menon N, van der Meulen Rodgers Y, Nguyen H (2014) Women's land rights and children's human capital in Vietnam. World Dev 54:18 31

Milà i Canals L, Chenoweth J, Chapagain A, Orr S, Antón A, Clift R (2009) Assessing freshwater use impacts in LCA: part I-inventory modelling and characterisation factors for the main impact pathways. Int J Life Cycle Assess 14(1):28-42

Miller TG, Spoolman SE (2013) Environmental science. Brooks/Cloe, Belmont

Musaazi MK, Mechtenberg AR, Nakibuule J, Sensenig R, Miyingo E, Makanda JV, Hakimian A, Eckelman MJ (2014) Quantification of social equity in life cycle assessment for increased sustainable production of sanitary products in Uganda. J Clean Prod. doi:10. 1016/j.jclepro.2013.10.026

Nabe-Nielsen K, Kecklund G, Ingre M, Skotte J, Diderichsen F, Garde AH (2010) The importance of individual preferences when evaluating the associations between working hours and indicators of health and well-being. Appl Ergon 41(6):779-786

Newcombe RG (2007) Working hours and ill-health - a more serious relationship than it appears? Int J Cardiol 114:284-285

Niemeijer D, de Groot RS (2008) A conceptual framework for selecting environmental indicator sets. Ecol Indic 8(1):14-25

Nieuwenhuys O (1996) The paradox of child labour and anthropology. Annu Rev Anthropol 25:237-251

Noll H-H (2002) Towards a European system of social indicators: theoretical framework and system architecture. Soc Indic Res 58(1-3): $47-87$

Norris G (2006) Social impacts in product life cycles - towards life cycle attribute assessment. Int J Life Cycle Assess 11:97-104

O'Brien M, Doig A, Clift R (1996) Social and environmental life cycle assessment (SELCA). Int J Life Cycle Assess 1(4):231-237

Öncü E, Kurt AÖ, Esenay FI, Özer F (2013) Abuse of working children and influencing factors, Turkey. Child Abuse Negl 37(5):283-291

Parent J, Cucuzzella C, Revéret J-P (2010) Impact assessment in SLCA: sorting the sLCIA methods according to their outcomes. Int J Life Cycle Assess 15(2):164-171
Perrin RK (1999) Intellectual property rights and developing country agriculture. Agric Econ 21(3):221-229

Rai V, Schultz K, Funkhouser E (2014) International low carbon technology transfer: do intellectual property regimes matter? Glob Environ Chang 24:60-74

Rametsteiner E, Pülzl H, Alkan-Olsson J, Frederiksen P (2011) Sustainability indicator development - science or political negotiation? Ecol Indic 11(1):61-70

Ranjan P (1999) An economic analysis of child labor. Econ Lett 64(1): 99-105

Raposo PS, van Ours JC (2010) How working time reduction affects jobs and wages. Econ Lett 106(1):61-63

Rojas M, Vegas Z, Briceno L, Rodriguez L, Rojas M, Vegas Z, Briceno L, Rodriguez L (2010) Child labor and health: exploratory study from a public market in Valencia, Venezuela. Toxicol Lett 196(Suppl (0)): S69

Rosenberg J, Weiss A (2012) Property rights and institutions in biblical society: the purchase of the Cave of the Patriarchs. Eur J Polit Econ 28(3):279-285

Saint-Paul G (2004) Are intellectual property rights unfair? Labour Econ 11(1):129-144

Sánchez R (2013) Do reductions of standard hours affect employment transitions? Evidence from Chile. Labour Econ 20:24-37

Snir R, Harpaz I (2012) Beyond workaholism: towards a general model of heavy work investment. Hum Resour Manag Rev 22(3):232-243

S-t L (2011) Strengthening intellectual property rights: experience from the 1986 Taiwanese patent reforms. Int J Ind Organ 29(5):524-536

Unruh JD (2002) Poverty and property rights in the developing world: not as simple as we would like. Land Use Policy 19(4):275-276

Valdivia S, Ugaya CL, Hildenbrand J, Traverso M, Mazijn B, Sonnemann G (2013) A UNEP/SETAC approach towards a life cycle sustainability assessment - our contribution to Rio+20. Int J Life Cycle Assess 18(9):1673-1685

Voigt S, Gutmann J (2013) Turning cheap talk into economic growth: on the relationship between property rights and judicial independence. $\mathrm{J}$ Comp Econ 41(1):66-73

von der Dunk FG, Back-Impallomeni E, Hobe S, Ramirez de Arellano RM (2004) Surreal estate: addressing the issue of 'Immovable Property Rights on the Moon'. Space Policy 20(3):149-156

Weidema B (2006) The integration of economic and social aspects in life cycle impact assessment. Int J Life Cycle Assess 11:89-96

Weldegiorgis FS, Franks DM (2014) Social dimensions of energy supply alternatives in steelmaking: comparison of biomass and coal production scenarios in Australia. J Clean Prod. doi:10.1016/j.jclepro. 2013.09.056

Wolff F-C, Maliki (2008) Evidence on the impact of child labor on child health in Indonesia, 1993-2000. Econ Hum Biol 6(1): 143-169

Wunder C, Heineck G (2013) Working time preferences, hours mismatch and well-being of couples: are there spillovers? Labour Econ 24: 244-252 
Reproduced with permission of the copyright owner. Further reproduction prohibited without permission. 